\title{
等式と不等式制約をもつ最適化問題の大域最適化手法と その 2 レベル計画問題への応用
}

\author{
呂
}

敏*・志 水 清 孝*

\author{
A Global Optimization Technique for Solving a Nonlinear Programming Problem \\ with Equality and Inequality Constraints and Its Application \\ to the Bilevel Programming Problem
}

Min LU* and Kiyotaka SHIMIzU*

\begin{abstract}
A global optimization technique is proposed for solving a nonlinear programming problem with equality and inequality constraints by using the concept of exterior penalty method. The original problem is transformed into an auxiliary problem which is an optimization problem with inequality constraints only. It is proved that the global optimal solution can be obtained as an accumulation point of a sequence of solutions to the auxiliary problems, as the penalty parameter goes to the infinite. Under appropriate assumptions, we show that the auxiliary problem can be equivalently transformed to a concave program for which we can find a global optimal solution.

It is then applied to solve the bilevel programming problem. We replace the low-level problem by its Kuhn-Tucker conditions, and obtain a nonlinear programming problem with equality and inequality constraints. Then, by applying the above technique, a global optimal solution to the bilevel programming problem is found in the case of convex quadratic lower-level problem.
\end{abstract}

Key Words : global optimization, nonlinear programming problem, exterior penalty method, concave program, bilevel programming problem

\section{1.はじめに}

等式と不等式制約をもつ最適化問題の大域最適化手法 について考元る。このような問題は目的関数と制約関数 すべてが凸関数であっても，一般には凸計画問題ではな く, 通常の最適化手法ではその大域最適解を求めること が困難である。ところが，無制約最適化問題や不等式制 約をもつ最適化問題などの非凸計画問題に対しては，大 域最適化手法が数多く提案されている ${ }^{1,2)}$. 特に, 不等式 制約をもつ最適化問題に関しては，制約関数が凸関数で 目的関数が凹関数であるような凹計画問題に対する研究 がさかんに行われ，多くの計算手法が与えられてい る2),3).これに対し，等式と不等式制約をもつ最適化問題

\footnotetext{
* 慶応義塾大学理工学部 横浜市港北区日吉 3-14-1

* Faculty of Science and Technology, Keio University, Yokohama

(Received September 9, 1991)

(Revised February 10, 1992)
}

に対する大域最適化手法はまだ提案されていない. そこで,ここでは外点ペナルティ法の考え方を適用し 等式と不等式制約をもつ問題の大域最適解を求めること を考える、この手法では，等式と不等式制約をもつ元問 題を不等式制約だけをもつ問題に変換し, ペナルティ・ パラメー夕を無限大にしたとき, 補助問題の大域最適解 が元問題の大域最適解に収束するようにする。このこと は通常の外点ペナルティ法 (たとえば, 文献 4) あるいは 文献 5)の 6.2.2 節参照)の性質とほとんど同様に証明する ことができる、等式と不等式制約をもつ問題を不等式制 約をもつ補助問題に変換して解く手法は Mayne-Polak ${ }^{6}$ ) も用いているが，そこでは目的関数と制約関数が連続微 分可能で, かつ 1 次独立の制約想定が成り立つ仮定のも とで補助問題の局所最適解と元問題の局所最適解との関 係について論じている。これに対し，ここでは，目的関 数と制約関数の連続性だけを仮定して補助問題の大域最 適解と元問題の大域最適解との関係について考える. 
つぎに，補助問題の大域最適化を考える．まず，目的 関数と制約関数がともに凸関数である場合を考える．こ のとき補助問題が凸制約集合のもとでの凸関数の差の最 小化問題であり,さらに大域最適解が求められる凹計画 問題に等価変換できることを示す.そのあと，目的関数 と制約関数が凸関数の差であるときでも，ここで提案し ているぺナルティ法の補助問題を凹計画問題に等価変換 できることを説明する.

さらに，この手法を 2 レベル計画問題に応用すること を考える，2レベル計画問題には先手と後手からなる非 ゼロ和ゲーム問題である Stackelberg 問題7)などがあ る.このような問題はかりに，上位と下位の目的関数と 制約関数が凸あるいは仮定をもっと強めて線形であって も, 問題全体が非凸計画問題となる，2レベル計画問題 の計算手法は過去にも提案されている8) 10). 文献 8 ) の夕゙ ブル・ペナルティ法は 2 レベル計画問題を無制約計画問 題に変換して解くが，そこでは下位問題の大域最適解が 求まることを前提としている. 文献 9 )の混合整数計画問 題に変換して解く手法は 2 レベル線形計画問題に関する 手法であり, 文献 10)の分枝限定法は下位問題が 2 次凸 計画問題である 2 レベル凸計画問題に関する手法である が，これらはいずれも 2 レベル計画問題を解くかわりに 下位問題を Kuhn-Tucker 条件で置き換えた非線形計画 問題を解くことを考える.Kuhn-Tucker 条件の中に相 補性条件があるため, 得られた問題が非凸計画問題であ る. そのため, 文献 9 ) では下位制約式の個数と同じ個数 の 0-1 変数を取り入れて, 混合整数計画問題に対する手 法でその大域最適解を求める. また, 文献 10)では相補性 条件の中の Kuhn-Tucker 乗数が 0 であることと下位制 約式が活性であることとのすべての組合せを陰伏的に考 えるために分枝限定法を用いているが，本質は下位の制 約式の個数と同じ個数の 0-1 変数を取り入れたことと同 様である，これらに対し，本論文では，まず下位問題を その Kuhn-Tucker 条件で置き換えて, 等式と不等式制 約をもつ最適化問題を得る。そして，上記の手法を応用 することによって, 下位問題が 2 次凸計画問題であると きの 2 レベル計画問題の大域最適解を求める.この手法 は文献 9)，10）と違って,一つの補助変数を取り入れるだ けで済む. 数值例でこの手法の有効性が検証された。

\section{2. 元問題と補助問題との関係}

等式と不等式制約をもつ最適化問題

$$
\min _{x} f(\boldsymbol{x})
$$

subj. to $\boldsymbol{g}(\boldsymbol{x}) \leqq \mathbf{0}$

$$
\boldsymbol{h}(\boldsymbol{x})=0
$$

を考える.ただし, $\boldsymbol{x} \in R^{n}, f: R^{n} \rightarrow R^{1}, \boldsymbol{g}: R^{n} \rightarrow R^{m}, \boldsymbol{h}:$ $R^{n} \rightarrow R^{l}$ とする.

問題 (1)に対し，つぎのような補助問題を考える.

$$
\begin{gathered}
\min _{x} f(\boldsymbol{x})+s \Phi(\boldsymbol{h}(\boldsymbol{x})) \\
\text { subj. to } \boldsymbol{g}(\boldsymbol{x}) \leqq \mathbf{0} \\
\boldsymbol{h}(\boldsymbol{x}) \leqq \mathbf{0}
\end{gathered}
$$

ただし， $s>0$ はペナルティ・パラメータ, $\Phi: R^{l} \rightarrow R^{1}$ は ペナルティ関数でつぎのような性質をもつ.

$$
\begin{aligned}
& \Phi(\boldsymbol{h}(\boldsymbol{x}))=0, \boldsymbol{h}(\boldsymbol{x})=\mathbf{0} \text { のとき } \\
& \Phi(\boldsymbol{h}(\boldsymbol{x}))>0, \boldsymbol{h}(\boldsymbol{x}) \leq \mathbf{0} \text { (注 1) のとき }
\end{aligned}
$$

このような関数の具体例としては,

$$
\Phi(\boldsymbol{h})=\sum_{j=1}^{l}\left(-h_{j}\right)^{\alpha}, \alpha=1,2, \cdots
$$

などがある。

(4) 式において $\alpha=1$ のとき, 問題 (2)は文献 6)の補 助問題と一致している.ところが, ここでは, 文献 6 ) と 違って，関数の連続微分可能性と 1 次独立の制約想定を 仮定しないで問題 $(1$ ) と問題 $(2)$ との関係を考える.

【定理 1】問題 (1)の大域最適解 $\boldsymbol{x}^{o}$ が存在し, かつ 0 $<s^{k}<s^{k+1}$ なる二つのパラメー夕 $s^{k}, s^{k+1}$ に対する問題 ( 2 ) の大域最適解 $\boldsymbol{x}^{k}, \boldsymbol{x}^{k+1}$ が存在すると仮定する.この とき，つぎのことが成り立つ。

(i ) $f\left(\boldsymbol{x}^{k}\right)+s^{k} \Phi\left(\boldsymbol{h}\left(\boldsymbol{x}^{k}\right)\right)$

$$
\leqq f\left(\boldsymbol{x}^{k+1}\right)+s^{k+1} \Phi\left(\boldsymbol{h}\left(\boldsymbol{x}^{k+1}\right)\right) \leqq f\left(\boldsymbol{x}^{o}\right),
$$

(ii) $\Phi\left(\boldsymbol{h}\left(\boldsymbol{x}^{k}\right)\right) \geqq \Phi\left(\boldsymbol{h}\left(\boldsymbol{x}^{k+1}\right)\right)$,

(iii). $f\left(x^{k}\right) \leqq f\left(x^{k+1}\right) \leqq f\left(x^{o}\right)$.

(証明) 外点ペナルティ法としてよく知られている定 理とほとんど同様に証明できる(たとえば，文献 5)の定 理 6.8 の証明を参照).

この手法の収束性に関する基本定理を与えるために， つぎの仮定をおく.

仮定 1) ある正数 $\varepsilon$ が存在して，集合

$$
\begin{aligned}
X^{\varepsilon}= & \left\{\boldsymbol{x} \mid g_{i}(\boldsymbol{x}) \leqq 0, i=1, \cdots, m,\right. \\
& \left.-\varepsilon \leqq h_{j}(\boldsymbol{x}) \leqq 0, j=1, \cdots, l\right\}
\end{aligned}
$$

がコンパクトである.

このとき，つぎの定理が得られる.

【定理 2】問題 $(1)$ および, 任意の $s>0$ に対する問題 （2）に大域最適解が存在すると仮定する。このとき, 仮 定 1)が成り立ち, かつ関数 $f, \boldsymbol{g}, \boldsymbol{h}$ および $\Phi$ が各定義域 上で連続ならば, 狭義単調増加して無限大に発散する $s$ (つまり, $k \rightarrow \infty$ のとき, $s^{k} \rightarrow \infty$ ) の正数列 $\left\{s^{k}\right\}$ に対する 問題 ( 2 )の大域最適解の点列 $\left\{\boldsymbol{x}^{k}\right\}$ に集積点が存在し, か つ任意の集積点は問題 (1)の大域最適解である.

（証明）（集積点の存在と許容性). 定理 1 の（i )と

（注 1） $\quad \boldsymbol{a} \leq \boldsymbol{b} \Longleftrightarrow$ すべての $i \in\{1, \cdots, l\}$ に対し $a_{i} \leqq b_{i}$ かつ 少なくとも一つの $i$ に対し $q_{i}<b_{i}$. 
（iii）より 数列 $\left\{f\left(\boldsymbol{x}^{k}\right)+s^{k} \boldsymbol{\Phi}\left(\boldsymbol{h}\left(\boldsymbol{x}^{k}\right)\right)\right\},\left\{f\left(\boldsymbol{x}^{k}\right)\right\}$ は上界を もつ単調増加数列だから, それぞれにある極限 $p^{*}, f^{*}$ が存 在し, $0 \leqq p^{*}-f^{*}=\lim _{k \rightarrow \infty} S^{k} \Phi\left(\boldsymbol{h}\left(\boldsymbol{x}^{k}\right)\right)$ が成り立つ. $k \rightarrow \infty$ のとき, $s^{k} \rightarrow \infty$ だか,

$$
\lim _{\boldsymbol{k} \rightarrow \infty} \Phi\left(\boldsymbol{h}\left(\boldsymbol{x}^{k}\right)\right)=0
$$

が必要である. 連続性の仮定より, $\Phi(\boldsymbol{h}(\boldsymbol{x}))$ が $\boldsymbol{x}$ に関し て連続だから， $x^{k} \in X^{\varepsilon} \forall k>K^{\varepsilon}$ なる自然数 $K^{\varepsilon}$ が存在 する. $X^{\varepsilon}$ のコンパクト性より, 点列 $\left\{x^{k}\right\}$ には集積点と これに収束する部分点列が存在する。その任意の集積点 を $\tilde{\boldsymbol{x}}$ とすると，(5)式より，

$$
\Phi(\boldsymbol{h}(\tilde{\boldsymbol{x}}))=0
$$

が得られる.また，仮定 1)より，

$$
\begin{aligned}
& g_{i}(\tilde{\boldsymbol{x}}) \leqq 0, i=1, \cdots, m \\
& -\varepsilon \leqq h_{j}(\tilde{\boldsymbol{x}}) \leqq 0, j=1, \cdots, l
\end{aligned}
$$

が得られる. (7) 式, (6)式と ( 3 ) 式より, $\tilde{\boldsymbol{x}}$ が問題(1) の許容解であることがわかる.

(集積点の最適性). $\tilde{\boldsymbol{x}}$ の許容性より, 問題( 1 )の大域 最適解 $\boldsymbol{x}^{o}$ に対し,

$$
f\left(x^{o}\right) \leqq f(\tilde{x})
$$

が成り立つ.一方, $\tilde{x}$ に収束する部分点列を改めて $\left\{x^{k}\right\}$ とすると, 定理 1 の(iii)よりすべての $k$ に対し $f\left(x^{k}\right)$ $\leqq f\left(x^{o}\right)$ である.このことと $f$ の連続性より，

$$
\lim _{k \rightarrow \infty} f\left(\boldsymbol{x}^{k}\right)=f(\tilde{\boldsymbol{x}}) \leqq f\left(\boldsymbol{x}^{o}\right)
$$

が成り立つ。よって，

$$
f(\tilde{x})=f\left(x^{\circ}\right)
$$

となり, $\tilde{\boldsymbol{x}}$ が問題 (1)の大域最適解である.

定理 2 より, ペナルティ・パラメータが無限大に発散 するとき, 問題 ( 2 ) の大域最適解が元問題 ( 1 ) の大域最 適解に収束することがわかる。

定理 1 と定理 2 より，つぎの定理が得られる。

【定理 3】問題 (1) および, 任意の $s>0$ に対する問題 (2) に大域最適解が存在すると仮定する。 また，仮定 1) が成り立ち, かつ関数 $f, \boldsymbol{g}, \boldsymbol{h}$ および $\Phi$ が各定義域上で 連続であるとし, 狭義単調増加して無限大に発散する $s$ (つまり, $k \rightarrow \infty$ のとき, $\left.s^{k} \rightarrow \infty\right)$ の正数列 $\left\{s^{k}\right\}$ に対する 問題 ( 2 )の大域最適解の点列を $\left\{\boldsymbol{x}^{k}\right\}$ とする.このとき, 問題 (1)の大域最適解 $\boldsymbol{x}^{\circ}$ に対し，つぎのことが成り立 ว.

(i ) $\lim _{k \rightarrow \infty} f\left(x^{k}\right)=f\left(x^{o}\right)$,

(ii) $\lim _{k \rightarrow \infty} s^{k} \Phi\left(\boldsymbol{h}\left(\boldsymbol{x}^{k}\right)\right)=0$.

（証明）文献 5)の定理 6.10 の証明を参照.

この手法で問題 ( 1 )の大域最適解を求めるための計算 手順はつぎのとおりである.

Step 1 初期パラメー夕 $s^{1}$ を選び, $k=1$ とする.

Step 2 不等式制約だけをもつ補助問題 (2)を解き，そ
の大域最適解を $\boldsymbol{x}^{k}$ とする。

Step 3 もし $s^{k} \Phi\left(\boldsymbol{h}\left(\boldsymbol{x}^{k}\right)\right)<\delta$ ならば， $\boldsymbol{x}^{k}$ を問題 (1)の 大域最適解として終了する.さもなければ, Step 4 へ. ただし， $\delta$ は十分小さな正数である。

Step $4 s^{k+1}:=\beta s^{k}$ とし, $k:=k+1$ として Step $2 へ$. ただし， $\beta>1$ は定数である。

Step 3 の終了判定は定理 3 (ii)によるものである.ま た, Step 2 において不等式制約だけをもつ補助問題 $(2)$ の大域最適解を求めなければならないが，つぎに適当な 仮定のもとで補助問題 (2)の大域最適化を考える.

\section{3. 補助問題の大域最適化}

\section{$3.1 f, g, h$ が凸関数である場合}

このとき（4)式において $\alpha=1$ ととると,つまり, ぺ ナルティ関数を $\Phi(\boldsymbol{h}(\boldsymbol{x}))=\sum_{j=1}^{l}\left(-h_{j}(\boldsymbol{x})\right)$ ととると, 補 助問題 $(2)$ がつぎのようになる。

$$
\begin{aligned}
& \min _{\boldsymbol{x}} f(\boldsymbol{x})=s \sum_{j=1}^{l}\left(-h_{j}(\boldsymbol{x})\right)=f(\boldsymbol{x})-s \sum_{j=1}^{l} h_{j}(\boldsymbol{x}) \\
& \text { subj. to } \boldsymbol{g}(\boldsymbol{x}) \leqq \mathbf{0} \\
& \boldsymbol{h}(\boldsymbol{x}) \leqq \mathbf{0}
\end{aligned}
$$

$f, \boldsymbol{g}, \boldsymbol{h}$ が凸である場合, ペナルティ・パラメータ $s$ が与 えられたもとで,問題 $(8)$ の制約集合は凸集合であるが， 目的関数は凸関数の差になっている.

つぎに, 問題 $(8)$ のつぎのような関連問題を考える.

$$
\begin{array}{r}
\min _{\boldsymbol{x}, t} t-s \sum_{j=1}^{l} h_{j}(\boldsymbol{x}) \\
\text { subj. to } f(x) \leqq t \\
\boldsymbol{g}(\boldsymbol{x}) \leqq \mathbf{0} \\
\boldsymbol{h}(\boldsymbol{x}) \leqq \mathbf{0}
\end{array}
$$

$f, \boldsymbol{g}, \boldsymbol{h}$ が凸である場合, 問題 ( 9 )は目的関数が凹関数, 制約集合が凸集合であるいわゆる凹計画問題である.

問題 $(8)$ と問題 $(9)$ の関係に関して, つぎの定理が成 り立つ.

【定理 4】問題 $(8)$ と問題 (9) は等価である.つまり, (i ) $\boldsymbol{x}^{o}$ が問題 ( 8 )の大域最適解ならば, 必ず $\left(\boldsymbol{x}^{o}, t^{\circ}\right)$ が問題 ( 9 )の大域最適解となるような $t^{o} \in R^{1}$ が 存在する.

(ii ) $\left(\boldsymbol{x}^{o}, t^{o}\right)$ が問題 ( 9$)$ の大域最適解ならば, $\boldsymbol{x}^{o}$ が問 題 ( 8 ) の大域最適解である.

(証明) ( i ) $t^{o}=f\left(\boldsymbol{x}^{o}\right)$ とすると, 明らかに $\left(\boldsymbol{x}^{o}\right.$, $\left.t^{o}\right)$ が問題 $(9)$ の許容解である.もし, $\left(x^{o}, t^{o}\right)$ が問題

(9)の大域最適解でなければ,

$$
\begin{aligned}
& t^{\prime}-s \sum_{j=1}^{l} h_{j}\left(\boldsymbol{x}^{\prime}\right)<t^{o}-s \sum_{j=1}^{l} h_{j}\left(\boldsymbol{x}^{\circ}\right) \\
& f\left(\boldsymbol{x}^{\prime}\right) \leqq t^{\prime} \\
& \boldsymbol{g}\left(\boldsymbol{x}^{\prime}\right) \leqq \mathbf{0}, \boldsymbol{h}\left(\boldsymbol{x}^{\prime}\right) \leqq \mathbf{0}
\end{aligned}
$$


なるような $\left(x^{\prime}, t^{\prime}\right)$ が存在する，このとき，(10.c)より， $\boldsymbol{x}^{\prime}$ が問題 $(8)$ の許容解である。 また,

$$
\begin{aligned}
f\left(\boldsymbol{x}^{\prime}\right)-s \sum_{j=1}^{l} h_{j}\left(\boldsymbol{x}^{\prime}\right) & \leqq t^{\prime}-s \sum_{j=1}^{l} h_{j}\left(\boldsymbol{x}^{\prime}\right) \\
& <t^{o}-s \sum_{j=1}^{l} h_{j}\left(\boldsymbol{x}^{\circ}\right) \\
& =f\left(\boldsymbol{x}^{o}\right)-s \sum_{j=1}^{l} h_{j}\left(\boldsymbol{x}^{o}\right)
\end{aligned}
$$

となる.これは $x^{o}$ が問題 ( 8 ) の大域最適解であること に矛盾する.よって, $\left(\boldsymbol{x}^{o}, t^{o}\right)$ が問題 $(9)$ の大域最適解で ある。

(ii) 背理法で証明する. $\boldsymbol{x}^{o}$ が問題 ( 8 )の大域最適解 でないとすると，

$$
\begin{aligned}
& f\left(\boldsymbol{x}^{\prime}\right)-s \sum_{j=1}^{l} h_{j}\left(\boldsymbol{x}^{\prime}\right)<f\left(\boldsymbol{x}^{o}\right)-s \sum_{j=1}^{l} h_{j}\left(\boldsymbol{x}^{o}\right) \\
& \boldsymbol{g}\left(\boldsymbol{x}^{\prime}\right) \leqq \mathbf{0}, \boldsymbol{h}\left(\boldsymbol{x}^{\prime}\right) \leqq \mathbf{0}
\end{aligned}
$$

となるような $x^{\prime}$ が存在する. $t^{\prime}=f\left(x^{\prime}\right)$ とおくと, $\left(x^{\prime}, t^{\prime}\right)$ は問題 $(9)$ の許容解であり, かつ,

$$
\begin{aligned}
t^{\prime}-s \sum_{j=1}^{l} h_{j}\left(\boldsymbol{x}^{\prime}\right) & =f\left(\boldsymbol{x}^{\prime}\right)-s \sum_{j=1}^{l} h_{j}\left(\boldsymbol{x}^{\prime}\right) \\
& <f\left(\boldsymbol{x}^{o}\right)-s \sum_{j=1}^{l} h_{j}\left(\boldsymbol{x}^{o}\right) \\
& \leqq t^{o}-s \sum_{j=1}^{l} h_{j}\left(\boldsymbol{x}^{o}\right)
\end{aligned}
$$

となる。これは $\left(\boldsymbol{x}^{o}, t^{o}\right)$ が問題 $(9)$ の大域最適解である ことに矛盾する.よって, $x^{\circ}$ が問題 $(8)$ の大域最適解で ある・

この定理より,補助問題 $(8)$ を解くかわりに, 問題 $(9)$ を解くことができる. $f, \boldsymbol{g}, \boldsymbol{h}$ が凸である場合, 問題 ( 9 ) は凹計画問題となる.それゆえ, 文献 2)のPART B で述 べた手法(具体的に，文献 11)の支持超平面法や文献 12) の分離超平面法など）でその大域最適解を求めることが でき,さらに 2 章のペナルティ法を用いれば元問題の大 域最適解がもとまることを期待できる。

つぎに簡単な数值例を用いて本手法の有効性を示す.

[例題 1 ]

$$
\begin{array}{cl}
\min _{x} 3\left(x_{1}-1\right)^{2}+3\left(x_{2}-0.5\right)^{2} \\
\text { subj. to } & -0.5 x_{1}+x_{2} \leqq 1 \\
& 0.5 x_{1}-x_{2} \leqq 1 \\
& x_{1}^{2}+x_{2}^{2}-4=0
\end{array}
$$

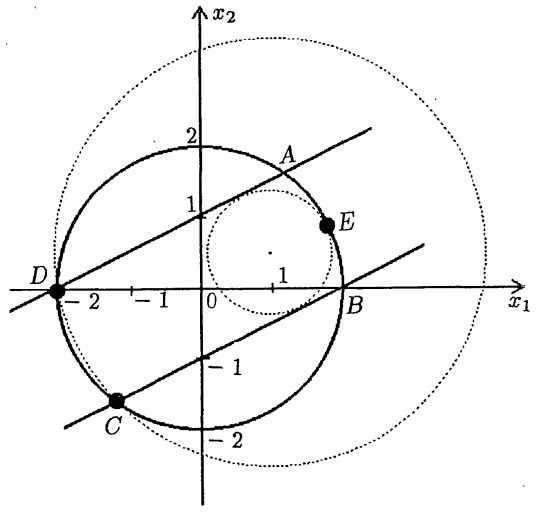

Fig. 1 Feasible solution set and optimal solutions of example 1

この問題の許容解集合は Fig. 1 の $\overparen{A B}, \overparen{C D}$ の上の点か らなる集合であり, 凸ではない. またこの問題にはつぎ のような三つの局所最小解が存在する.

$$
C(-1.2,-1.6)^{T}, D(-2,0)^{T}, E(4 / \sqrt{5}, 2 / \sqrt{5})^{T}
$$
その中で, $E(4 / \sqrt{5}, 2 \sqrt{5})^{T}$ が大域最小解である (Fig. 1 参照).

例題 1 のような等式と不等式制約をもつ問題に対する 大域最適化手法は, 過去には提案されていない. そこで, 上記の手法でその大域最適解を求める。まず，つぎのよ うな凹計画問題

$$
\begin{array}{ll}
\min _{x, t} t-s & \left(x_{1}^{2}+x_{2}^{2}-4\right) \\
\text { subj. to } & 3\left(x_{1}-1\right)^{2}+3\left(x_{2}-0.5\right)^{2}-t \leqq 0 \\
& -0.5 x_{1}+x_{2} \leqq 1 \\
& 0.5 x_{1}-x_{2} \leqq 1 \\
& x_{1}^{2}+x_{2}^{2}-4 \leqq 0
\end{array}
$$

を構成する. $s$ が与えられたとき, 支持超平面法 ${ }^{11)}$ や分離 超平面法 ${ }^{12)}$ でこの凹計画問題の大域最適解を求めるこ とができ，ここでは分離超平面法を用いる。これによっ て, Table 1 のような結果を得た。 ただし, Table 1 にお いて, $k$ はイテレーション番号で, $f^{k}=f\left(x^{k}\right), h^{k}=h\left(x^{k}\right)$ である. Table 1 より, 例題 1 の大域最適解が得られたこ とがわかる. また, 目的関数值 $f\left(\boldsymbol{x}^{k}\right)$, 拡大目的関数值 $f\left(x^{k}\right)-s^{k} h\left(x^{k}\right)$ は $k$ に関して単調増加, ペナルティ関

Table 1 Computational results of example 1

\begin{tabular}{c|c|c|c|c|c|c|c}
\hline \hline$k$ & $s^{k}$ & $\left(x_{1}^{k}, x_{2}^{k}\right)$ & $t^{k}$ & $f^{k}$ & $-h^{k}$ & $-s^{k} h^{k}$ & $f^{k}-s^{k} h^{k}$ \\
\hline 1 & 0.01 & $(1.003,0.502)$ & 0.000 & 0.000 & 2.743 & 0.027 & 0.027 \\
\hline 2 & 0.05 & $(1.017,0.509)$ & 0.001 & 0.001 & 2.706 & 0.135 & 0.136 \\
\hline 3 & 0.25 & $(1.094,0.545)$ & 0.032 & 0.032 & 2.507 & 0.627 & 0.659 \\
\hline 4 & 1.25 & $(1.714,0.856)$ & 1.911 & 1.911 & 0.328 & 0.410 & 2.321 \\
\hline 5 & 6.25 & $(1.789,0.894)$ & 2.334 & 2.334 & 0.000 & 0.000 & 2.333 \\
\hline \multicolumn{2}{c}{ true values } & $(1.789,0.894)$ & - & 2.334 & 0 & - & - \\
\hline
\end{tabular}


数値 $\Phi\left(h\left(x^{k}\right)\right)=-h\left(x^{k}\right)$ は $k$ に関して単調減少である ことも検証された.

\section{2 若干の拡張}

3.1 節の仮定をすこし緩めて,たとえば, $\boldsymbol{g}$ が凸関数で あるが, $f, \boldsymbol{h}$ が凸関数の差である場合を考える， $\boldsymbol{h}(\boldsymbol{x})$ $=0$ と $\sum_{j=1}^{l}\left|h_{j}(x)\right|=0$ が等価であるので, $h(x)=0$ を考え るかわりに, $\sum_{j=1}^{l}\left|h_{j}(x)\right|=0$ を考える.このとき, $h_{j}(x)$ $=h_{j}^{1}(x)-h_{j}^{2}(x), h_{j}^{1}, h_{j}^{2}$ が凸関数であるとすると, 文献 2) の定理 I. 7 より,

$$
\sum_{j=1}^{l}\left|h_{j}(x)\right|=h^{1}(x)-h^{2}(x)
$$

となる、ただし，

$$
\begin{aligned}
& h^{1}(x)=2 \sum_{j=1}^{l} \max \left\{h_{j}^{1}(x), h_{j}^{2}(x)\right\} \\
& h^{2}(x)=\sum_{j=1}^{l}\left(h_{j}^{1}(x)+h_{j}^{2}(x)\right)
\end{aligned}
$$

であり, $h^{1}, h^{2}$ が凸関数である. $f(x)=f^{1}(x)-f^{2}(x), f^{1}$, $f^{2}$ が凸関数であるとすると, 問題 $(1)$ は

$$
\begin{array}{ll}
\min _{\boldsymbol{x}, \boldsymbol{z}} f^{1}(\boldsymbol{x})-f^{2}(\boldsymbol{x}) \\
\text { subj. to } & \boldsymbol{g}(\boldsymbol{x}) \leqq \mathbf{0} \\
& h^{1}(\boldsymbol{x})-z=0 \\
& h^{2}(\boldsymbol{x})-z=0
\end{array}
$$

と等価である.このとき, 補助問題 $(8)$ は

$$
\begin{array}{ll}
\min _{\boldsymbol{x}, \boldsymbol{z}} f^{1}(\boldsymbol{x})-\left\{f^{2}(\boldsymbol{x})+s\left(h^{1}(\boldsymbol{x})+h^{2}(\boldsymbol{x})-2 z\right)\right\} \\
\text { subj. to } & \boldsymbol{g}(\boldsymbol{x}) \leqq \mathbf{0} \\
& h^{1}(\boldsymbol{x})-z \leqq 0 \\
& h^{2}(\boldsymbol{x})-z \leqq 0
\end{array}
$$

となり, 凸制約集合のもとでの凸関数の差の最小化問題 である. 定理 4 より,この問題は問題 (9)の形の山計画 問題に等価変換でき, 文献 2)のPART B で述べた手法 でその大域最適解を求めることができる.

もつと一般的に, $f, \boldsymbol{g}, \boldsymbol{h}$ すべてが凸関数の差である場 合を考える. $\boldsymbol{g}(\boldsymbol{x}) \leqq \mathbf{0}$ と $\max \left\{g_{i}(\boldsymbol{x}), i=1, \cdots, m\right\} \leqq 0$ が 等価であるので, $\boldsymbol{g}(x) \leqq 0$ を考えるかわりに, $\max$ $\left\{g_{i}(\boldsymbol{x}), i=1, \cdots, m\right\} \leqq 0$ を考える。まず, $g_{i}(\boldsymbol{x})=g_{i}^{1}(\boldsymbol{x})$ $-g_{i}^{2}(\boldsymbol{x}), g_{i}^{1}, g_{i}^{2}$ が凸関数であるとする.このとき, 文献 2) の定理 I. .7 より,

$$
\max \left\{g_{i}(\boldsymbol{x}), i=1, \cdots, m\right\}=g^{1}(\boldsymbol{x})-g^{2}(\boldsymbol{x})
$$

となる.ここで,

$$
\begin{aligned}
& g^{1}(\boldsymbol{x})=\max \left\{g_{i}^{1}(\boldsymbol{x})+\sum_{\substack{r=1 \\
r \neq i}}^{m} g_{r}^{2}(\boldsymbol{x}), i=1, \cdots, m\right\} \\
& g^{2}(\boldsymbol{x})=\sum_{i=1}^{m} g_{i}^{2}(\boldsymbol{x})
\end{aligned}
$$

であり, $g^{1}, g^{2}$ が凸関数である。また， $f(x)=f^{1}(x)$ $-f^{2}(x), h_{j}(x)=h_{j}^{1}(x)-h_{j}^{2}(x), f^{1}, f^{2}, h_{j}^{1}, h_{j}^{2}$ が凸関数で あるとすると, 問題 (1) は $\min _{\boldsymbol{x}} f^{1}(\boldsymbol{x})-f^{2}(\boldsymbol{x})$

subj. to $g^{1}(x)-g^{2}(x) \leqq 0$ $h_{j}^{1}(x)-h_{j}^{2}(x)=0, j=1, \cdots, l$

となり,さらに $g^{1}(x)-g^{2}(x)=z_{1}$ と置くと, $\min _{\boldsymbol{x}, z_{1}} f^{1}(\boldsymbol{x})-f^{2}(\boldsymbol{x})$

subj. to $z_{1} \leqq 0$

$$
\begin{aligned}
& g^{1}(x)-\left(g^{2}(x)+z_{1}\right)=0 \\
& h_{j}^{1}(x)-h_{j}^{2}(x)=0, j=1, \cdots, l
\end{aligned}
$$

と等価変換できる. 問題 (1.4)の不等式制約関数は凸関数 であり，等式制約関数と目的関数は凸関数の差である. 本節の冒頭の説明より, 問題 (14) は

$$
\begin{array}{ll}
\min _{x, z_{1}, z_{2}} f^{1}(x)-f^{2}(x) \\
\text { subj. to } & z_{1} \leqq 0 \\
& h^{A}\left(x, z_{1}\right)-z_{2}=0 \\
& h^{B}\left(x, z_{1}\right)-z_{2}=0
\end{array}
$$

と等価である.ここで,

$$
\begin{aligned}
& h^{A}\left(x, z_{1}\right)=2 \sum_{j=0}^{l} \max \left\{h_{j}^{1}\left(x, z_{1}\right), h_{j}^{2}\left(x, z_{1}\right)\right\} \\
& h^{B}\left(x, z_{1}\right)=\sum_{j=0}^{l}\left(h_{j}^{1}\left(x, z_{1}\right)+h_{j}^{2}\left(x, z_{1}\right)\right)
\end{aligned}
$$

でありただし，

$$
\begin{aligned}
& h_{0}^{1}\left(x, z_{1}\right)=g^{1}(x), h_{0}^{2}\left(x, z_{1}\right)=g^{2}(x)+z_{1}, \\
& h_{j}^{r}\left(x, z_{1}\right)=h_{j}^{r}(x), r=1,2, j=1, \cdots, l
\end{aligned}
$$

である。このとき, 補助問題 $(8)$ は

$$
\begin{aligned}
\min _{\boldsymbol{x}, z_{1}, z_{2}} f^{1}(\boldsymbol{x})-\left\{f^{2}(\boldsymbol{x})+s\right. & \left(h^{A}\left(\boldsymbol{x}, z_{1}\right)\right. \\
+ & \left.\left.h^{B}\left(\boldsymbol{x}, z_{1}\right)-2 z_{2}\right)\right\}
\end{aligned}
$$

subj. to $z_{1} \leqq 0$

$$
\begin{aligned}
& h^{A}\left(x, z_{1}\right)-z_{2} \leqq 0 \\
& h^{B}\left(x, z_{1}\right)-z_{2} \leqq 0
\end{aligned}
$$

となり, 凸制約集合のもとでの凸関数の差の最小化問題 である. 定理 4 より, この問題は問題 ( 9 )の形の凹計画 問題に等価変換でき, 文献 2)のPART B で述べた手法 でその大域最適解を求めることができる.

凸関数は凸関数の差という関数の特殊な場合であるた め, 3.1 節の場合はここの場合の特殊な場合とみること ができる.

この章では, 目的関数と制約関数が凸関数あるいは凸 関数の差であるという前提だけのもとで分析を行ってい る.これは Mayne-Polak ${ }^{6)}$ とは異なっていることに注意 しよう.

\section{2 レベル計画問題への応用}

2 レベル計画問題とは，未知パラメータに依存する下 位の計画問題と, このパラメータを決定変数とし, その 最適な值を上位独自の目的関数や制約関数により決める 
上位問題とからなり, しかも上位の決定が下位の最適解 を考慮して行われる問題である.このような問題には先 手と後手からなる非ゼロ和ゲーム問題である Stackelberg 問題7) などがある.

上位の決定変数を $\boldsymbol{x} \in R^{N}$ とし,下位の決定変数を $\boldsymbol{y} \in R^{n}$ とする.また, 上位の目的関数, 制約関数をそれぞれ $F$ : $R^{N+n} \rightarrow R^{1}, \boldsymbol{G}: R^{N+n} \rightarrow R^{M}$ とし, 下位の目的関数, 制約 関数をそれぞれ $f: R^{N+n} \rightarrow R^{1}, g: R^{N+n} \rightarrow R^{m}$ とする. このとき，2レベル計画問題はつぎのように定式化され る.

$$
\min _{\boldsymbol{x}} F(\boldsymbol{x}, \check{\boldsymbol{y}}(\boldsymbol{x}))
$$

subj. to $\quad G(x, \check{\boldsymbol{y}}(x)) \leqq 0$

$$
\begin{aligned}
f(\boldsymbol{x}, \check{\boldsymbol{y}}(\boldsymbol{x}))= & \min _{\boldsymbol{y}} f(\boldsymbol{x}, \boldsymbol{y}) \\
& \text { subj. to } \boldsymbol{g}(\boldsymbol{x}, \boldsymbol{y}) \leqq \mathbf{0}
\end{aligned}
$$

ただし, $\check{y}(x)$ は $x$ が与えられたもとでの下位問題 $(16$.

$\mathrm{c}, \mathrm{d})$ の最適解である. 以下では簡単のために, $\check{\boldsymbol{y}}(\boldsymbol{x})$ は 点対点写像で, つまり唯一解であるとする.

問題(16)に関して，つぎの仮定をおく.

仮定 2) $f, \boldsymbol{g}$ が $\boldsymbol{y}$ に関する連続微分可能な凸関数で ある.

仮定 3）（Slaterの制約想定） $x$ が与えられたとき， $\boldsymbol{g}(\boldsymbol{x}, \boldsymbol{y})<\boldsymbol{0}$ なる $\boldsymbol{y}$ が存在する.

このとき, 問題 $(16)$ がつぎのように等価変換できる.

$$
\begin{array}{ll}
\min _{\boldsymbol{x}, y, \boldsymbol{u}} F(\boldsymbol{x}, \boldsymbol{y}) \\
\text { subj. to } & \boldsymbol{G}(\boldsymbol{x}, \boldsymbol{y}) \leqq \mathbf{0} \\
& \boldsymbol{g}(\boldsymbol{x}, \boldsymbol{y}) \leqq \mathbf{0} \\
& \nabla_{y} f(\boldsymbol{x}, \boldsymbol{y})+\boldsymbol{u}^{T} \nabla_{y} \boldsymbol{g}(\boldsymbol{x}, \boldsymbol{y})=\mathbf{0} \\
& \boldsymbol{u}^{T} \boldsymbol{g}(\boldsymbol{x}, \boldsymbol{y})=0 \\
& \boldsymbol{u} \geqq \mathbf{0}
\end{array}
$$

ここで, 相補性条件 (17.e) が存在するために, $F, \boldsymbol{G}, f, \boldsymbol{g}$ に関する仮定をいかに強めても, 問題(17)が非凸計画問 題となり, 通常の数理計画法では大域最適解がもとまら ない.

以下ではつぎの仮定のもとで， 2 章で述べたぺナル ティ法を応用して変換問題 (17) を解くことを考える.

仮定 4) $F, \boldsymbol{G}$ が凸関数, $f$ が $\boldsymbol{y}$ に関して 2 次凸関数, $\boldsymbol{g}$ が線形関数である.

このとき，

$$
\begin{aligned}
& f(x, \boldsymbol{y})=\frac{1}{2} \boldsymbol{y}^{T} A_{0} \boldsymbol{y}+\left(\boldsymbol{x}^{T} B_{0}+\boldsymbol{c}_{0}^{T}\right) \boldsymbol{y}+p(\boldsymbol{x}) \\
& g_{i}(\boldsymbol{x}, \boldsymbol{y})=\boldsymbol{c}_{j}^{T} \boldsymbol{y}+\boldsymbol{d}_{j}^{T} \boldsymbol{x}+e_{j}, j=1, \cdots, m
\end{aligned}
$$

とする.ただし, $p(x)$ は任意の関数で, $A_{0} \geqq 0$ は非負定 值行列である.これによって，2レベル計画問題(16)の 変換問題 $(17)$ は

$$
\begin{array}{ll}
\min _{\boldsymbol{x}, y, \boldsymbol{u}} F(\boldsymbol{x}, \boldsymbol{y}) \\
\text { subj. to } & \boldsymbol{G}(\boldsymbol{x}, \boldsymbol{y}) \leqq \mathbf{0} \\
& \boldsymbol{c}_{j}^{T} \boldsymbol{y}+\boldsymbol{d}_{j}^{T} \boldsymbol{x}+e_{j} \leqq 0, j=1, \cdots, m \\
& A_{0}^{T} \boldsymbol{y}+B_{0}^{T} \boldsymbol{x}+\boldsymbol{c}_{0}+\left(\boldsymbol{c}_{1}, \cdots, \boldsymbol{c}_{m}\right) \boldsymbol{u} \\
& \sum_{j=1}^{m} u_{j}\left(\boldsymbol{c}_{j}^{T} \boldsymbol{y}+\boldsymbol{d}_{j}^{T} \boldsymbol{x}+e_{j}\right)=0 \\
& \boldsymbol{u} \geqq \mathbf{0}
\end{array}
$$$$
A_{0}^{T} \boldsymbol{y}+B_{0}^{T} \boldsymbol{x}+\boldsymbol{c}_{0}+\left(\boldsymbol{c}_{1}, \cdots, \boldsymbol{c}_{m}\right) \boldsymbol{u}=\mathbf{0}
$$

となる。この場合, 問題 (18)において, 相補性条件 (18.e) 以外の制約式によって規定されている領域は凸集合であ る.

$$
\text { ところが, 相補性条件 (18.e)の制約関数は }
$$

$$
\begin{aligned}
\sum_{j=1}^{m} u_{j}\left(\boldsymbol{c}_{j}^{T} \boldsymbol{y}+\boldsymbol{d}_{j}^{T} \boldsymbol{x}+e_{j}\right) & \\
= & \frac{1}{2}\left\{\sum_{j=1}^{m}\left[u_{j}^{2}+\left(\boldsymbol{c}_{j}^{T} \boldsymbol{y}+\boldsymbol{d}_{j}^{T} \boldsymbol{x}+e_{j}\right)^{2}\right]\right. \\
& \left.-\sum_{j=1}^{m}\left(u_{j}-\boldsymbol{c}_{j}^{T} \boldsymbol{y}-\boldsymbol{d}_{j}^{T} \boldsymbol{x}-e_{j}\right)^{2}\right\}
\end{aligned}
$$

と書き換えられる. $\boldsymbol{u} \geqq \mathbf{0}, \boldsymbol{c}_{j}^{T} \boldsymbol{y}+\boldsymbol{d}_{j}^{T} \boldsymbol{x}+e_{j} \leqq 0$ なので, 凸関 数の性質より, 関数 $\sum_{j=1}^{m}\left[u_{j}^{2}+\left(\boldsymbol{c}_{j}^{T} \boldsymbol{y}+\boldsymbol{d}_{j}^{T} \boldsymbol{x}+e_{j}\right)^{2}\right]$ と関数 $\sum_{j=1}^{m}\left(u_{j}-\boldsymbol{c}_{j}^{T} \boldsymbol{y}-\boldsymbol{d}_{j}^{T} \boldsymbol{x}-e_{j}\right)^{2}$ がともに凸関数である.つま り，相補性条件 (18.e)の制約関数は “凸関数の差” の形 に書き換えられる。このとき, 問題 (18) を問題 (12)の形 に等価変換してから 2 章のペナルティ法を適用してその 大域最適解を求めることができる，ところが，ここでは， $\boldsymbol{u} \geqq \mathbf{0}, \boldsymbol{c}_{j}^{T} \boldsymbol{y}+\boldsymbol{d}_{j}^{T} \boldsymbol{x}+e_{j} \leqq 0$ なので, かならず

$$
\sum_{j=1}^{m} u_{j}\left(\boldsymbol{c}_{j}^{T} \boldsymbol{y}+\boldsymbol{d}_{j}^{T} \boldsymbol{x}+e_{j}\right) \leqq 0
$$

となる.それゆえ, 問題 $(12)$ の形に変換しないで, 2 章の ペナルティ法を直接問題 (18) に適用するとき, その補助 問題（( 8$)$ に相当）の中の制約条件 $\sum_{j=1}^{m} u_{j}\left(\boldsymbol{c}_{j}^{T} \boldsymbol{y}+\boldsymbol{d}_{j}^{T} \boldsymbol{x}\right.$ $\left.+e_{j}\right) \leqq 0$ を省くことができる．したがって，問題 (18) に 変換 $(8)$ を施し, 相補性条件 (18.e) を目的関数に組み込 むと，その補助問題がつぎのような凸制約集合のもとで の凸関数の差の最小化問題になる.

$$
\begin{array}{cc}
\min _{\boldsymbol{x}, y, \boldsymbol{u}} F(\boldsymbol{x}, \boldsymbol{y})+s \sum_{j=1}^{m}\left(u_{j}-\boldsymbol{c}_{j}^{T} \boldsymbol{y}-\boldsymbol{d}_{j}^{T} \boldsymbol{x}-e_{j}\right)^{2} \\
-s \sum_{j=1}^{m}\left[u_{j}^{2}+\left(\boldsymbol{c}_{j}^{T} \boldsymbol{y}+\boldsymbol{d}_{j}^{T} \boldsymbol{x}+e_{j}\right)^{2}\right] \\
\text { subj. to } \quad \boldsymbol{G}(\boldsymbol{x}, \boldsymbol{y}) \leqq \mathbf{0} \\
& \boldsymbol{c}_{j}^{T} \boldsymbol{y}+\boldsymbol{d}_{j}^{T} \boldsymbol{x}+e_{j} \leqq 0, j=1, \cdots, m \\
& A_{0}^{T} \boldsymbol{y}+B_{0}^{T} \boldsymbol{x}+\boldsymbol{c}_{0}+\left(\boldsymbol{c}_{1}, \cdots, \boldsymbol{c}_{m}\right) \boldsymbol{u}=\mathbf{0} \\
& \boldsymbol{u} \geqq \mathbf{0}
\end{array}
$$

定理 4 より, この問題はつぎのような凹計画問題に等価 変換できる。 
$\min _{\boldsymbol{x}, \boldsymbol{y}, \boldsymbol{u}, t} t-s \sum_{j=1}^{m}\left[u_{j}^{2}+\left(\boldsymbol{c}_{j}^{T} \boldsymbol{y}+\boldsymbol{d}_{j}^{T} \boldsymbol{x}+e_{j}\right)^{2}\right]$

subj. to $F(\boldsymbol{x}, \boldsymbol{y})+s \sum_{j=1}^{m}\left(u_{j}-\boldsymbol{c}_{j}^{T} \boldsymbol{y}-\boldsymbol{d}_{j}^{T} \boldsymbol{x}-e_{j}\right)^{2} \leqq t$

$$
\begin{aligned}
& \boldsymbol{G}(\boldsymbol{x}, \boldsymbol{y}) \leqq \mathbf{0} \\
& \boldsymbol{c}_{j}^{T} \boldsymbol{y}+\boldsymbol{d}_{j}^{T} \boldsymbol{x}+e_{j} \leqq 0, j=1, \cdots, m \\
& A_{0}^{T} \boldsymbol{y}+B_{0}^{T} \boldsymbol{x}+\boldsymbol{c}_{0}+\left(\boldsymbol{c}_{1}, \cdots, \boldsymbol{c}_{m}\right) \boldsymbol{u}=\mathbf{0} \\
& \boldsymbol{u} \geqq \mathbf{0}
\end{aligned}
$$

ここでは，凹計画問題の制約集合が凸であることが大切 であり，線形等式制約があっても差し支えないことに注 意しよう. 問題 $(20)$ の制約条件に等式制約があるため, その制約集合に内点をもたない.そのため，問題 (20)を 解くとき，内点を必要とするような手法（たとえば，支 持超平面法 $\left.{ }^{11}\right)$ を用いることができない. $s$ が与えられた とき, 問題 (20)の大域最適解を凹計画問題に対する分離 超平面法 ${ }^{12)}$ などで計算できるので, 2 章の手法で問題 (18), ひいてはもとの 2 レベル計画問題 (16)の大域最適 解を求めることができる.

2 レベル計画問題の計算手法は文献 8)～10)にも与え られている. 文献 8)のダブル・ペナルティ法は下位問題 の大域最適解が求まることを前提としたもとで，大域最 適解に収束することを理論的に保証したが，数值計算で は最急降下法などの局所最適化手法を用いているため, 必ずしも大域最適解が得られるとは限らない. 文献 9)の 混合整数計画問題に変換して解く手法は $m$ 個の 0-1 変 数を取り入れている. 文献 10)の分枝限定法も本質は $m$ 個の 0-1変数を取り入れている。これらに比べ, 本手法 は補助変数 $t$ を取り入れるだけで，凹計画問題に対する 手法を用いて 2 レベル計画問題の大域最適解を求めるこ とができる，本手法の 2 レベル計画問題に対する有効性 を検証するためには，つぎの数值例について考える。

[例題 2 ]

$$
\begin{array}{ll}
\min _{x} 16 x^{2}+9(\check{y}(x))^{2} \\
\text { subj. to } \quad-4 x+\check{y}(x) \leqq 0 \\
x \geqq 0 \\
(x+\check{y}(x)-20)^{2} \\
=\min _{y}(x+y-20)^{2} \\
& \text { subj. to } 4 x+y-50 \leqq 0
\end{array}
$$

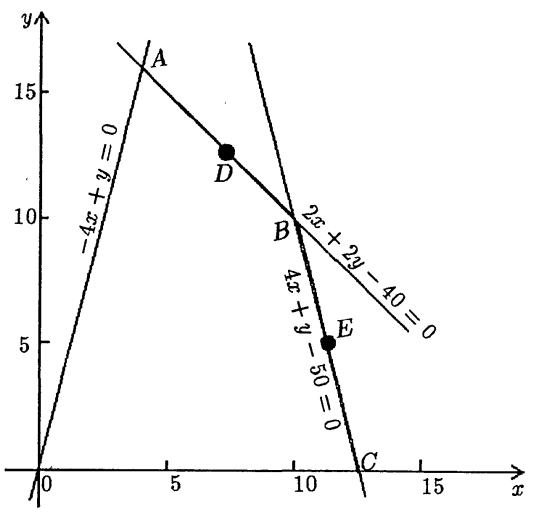

Fig. 2 Feasible solution set and optimal solutions of example 2

$$
y \geqq 0
$$

この問題の許容解集合は Fig. $\mathbf{2}$ の $A B, B C$ の上の点か らなる集合であり, 凸ではない。 また，この問題にはつ ぎの二つの局所最小解が存在する.

$$
D(7.2,12.8)^{T}, E(11.25,5)^{T}
$$

その中で, $E(11.25,5)^{T}$ が大域最小解である (Fig. 2 参 照).

この問題に対し, ダブル・ペナルティ法では, 必ずし も大域最適解が得られるとは限らない, また, 混合整数 計画問題に変換して解く手法や分枝限定法では, 非線形 混合整数計画問題を解く必要があり, 数值計算が煩雑で ある。そこで，上記の手法でその大域最適解を求める。 まず，つぎのような凹計画問題

$$
\begin{array}{lc}
\min _{x, y, u, t} t-s\left[u_{1}^{2}+(4 x+y-50)^{2}+u_{2}^{2}+y^{2}\right] \\
\text { subj. to } & 16 x^{2}+9 y^{2}+s\left[\left(u_{1}-4 x-y+50\right)^{2}\right. \\
& \left.+\left(u_{2}+y\right)^{2}\right]-t \leqq 0 \\
& -4 x+y \leqq 0 \\
& 4 x+y-50 \leqq 0 \\
& 2 x+2 y+u_{1}-u_{2}-40=0 \\
x, y, u_{1}, u_{2} \geqq 0
\end{array}
$$

を構成する. $s$ が与えられたとき, 分離超平面法 ${ }^{12)}$ その大域最適解を求めることができる。これによって, Table 2 のような結果を得た。ただし，Table 2 におい て, $k$ がイテレーション番号で, $F^{k}=F\left(x^{k}, y^{k}\right), h^{k}$ $=\sum_{j=1}^{2} u_{j}^{k} g_{j}\left(x^{k}, y^{k}\right)$ である.

Table 2 Computational results of example 2

\begin{tabular}{c|c|c|c|c|c|c|c|c}
\hline \hline$k$ & $s^{k}$ & $\left(x_{1}^{k}, x_{2}^{k}\right)$ & $\left(u_{1}^{k}, u_{2}^{k}\right)$ & $t^{k}$ & $F^{k}$ & $-h^{k}$ & $-s^{k} h^{k}$ & $F^{k}-s^{k} h^{k}$ \\
\hline 1 & 0.01 & $(0.000,0.000)$ & $(40.26,0.261)$ & 81.47 & 0.000 & 4026.1 & 40.26 & 40.26 \\
\hline 2 & 0.1 & $(0.000,0.000)$ & $(40.08,0.081)$ & 811.5 & 0.000 & 4008.1 & 400.8 & 400.8 \\
\hline 3 & 1.0 & $(11.25,5.000)$ & $(7.500,0.000)$ & 2331.3 & 2250.0 & 0.000 & 0.000 & 2250.0 \\
\hline \multicolumn{2}{l}{ true values } & $(11.25,5)$ & $(7.5,0)$ & - & 2250 & 0 & - & - \\
\hline
\end{tabular}


Table 2 より, 目的関数值 $F\left(x^{k}, y^{k}\right)$, 抎大目的関数值 $F\left(x^{k}, y^{k}\right)-s^{k} \sum_{j=1}^{2} u_{j}^{k} g_{j}\left(x^{k}, y^{k}\right)$ は $k$ に関して単調増加 し，またペナルティ関数值 $\Phi\left(h\left(x^{k}, y^{k}, u^{k}\right)\right)=-h\left(x^{k}\right.$, $\left.y^{k}, \boldsymbol{u}^{k}\right)=-\sum_{j=1}^{2} u_{j}^{k} g_{j}\left(x^{k}, y^{k}\right)$ は $k$ 関して単調減少し, かつ例題 2 の大域最適解が得られたことがわかる。

ここでは，上位目的関数 $F$ と制約関数 $G$ がともに凸 関数の差で, 下位問題 $(16 . c, d)$ が 2 次凸計画問題である 場合でも，2レベル計画問題 (16) の変換問題 (17) に対し 3.2 節の手法を用いればその補助問題を凹計画問題に等 価変換できることを付け加えておく。

\section{5.おわりに}

本論文ではまず，等式と不等式制約をもつ最適化問題 に対し，不等式制約だけをもつ補助問題をつくり，ペナ ルティ・パラメータが無限大に発散したとき, 補助問題 の大域最適解が元問題の大域最適解に収束することを証 明した。つぎに目的関数と制約関数が凸関数である場合 および凸関数の差である場合に, 補助問題が, 大域最適 解が求められる凹計画問題に等価変換でさることを説明 した。さらに適当な仮定のもとで 2 レべル計画問題を等 式と不等式制約をもつ問題に等価変換でき, 上記の手法 を適用してその大域最適解を求めることができることを 説明した。数值例でこの手法の有効性が確認された。

本論文の手法は，等式と不等式制約をもつ問題の大域 最適化の一手法を与えており, とくに, 数值計算が困難 である 2 レベル計画問題を凹計画問題に変換して解くこ とは有用な解法であるといえる。

\section{参 考 文 献}

1) A. Törn and A. Žilinskas: Global Optimization, Springer-Verlag (1989)

2) R. Horst and H. Tuy: Global Optimization-Deterministic Approaches, Springer-Verlag (1990)

3) R. Horst: Deterministic Methods in Constrained Global Optimization: Some Recent Advances and New Fields of Applications, Naval Research Logistics, 37, 433/471 (1990)

4) W. I. Zangwill: Nonlinear Programming via Penalty Functions, Management Science, 13, 344/358 (1967)
5) 志水, 相吉：数理計画法, 昭晃堂 (1984)

6) D. Q. Mayne and E. Polak: Feasible Directions Algorithms for Optimization Problems with Equality and Inequality Constraints, Mathematical Programming, 11, 67/80 (1976)

7) M. Simaan and J. B. Cruz: On the Stackelberg Strategy in Nonzero-sum Games, Journal of Optimization Theory and Applications, 11-5, 533/555 (1973)

8) E. Aiyoshi and K. Shimizu: A Solution Method for the Static Constrained Stackelberg Problem via Penalty Method, IEEE Trans. Automatic Control, AC-29-12, 1111/1114 (1984)

9) J. Fortuny-Amat and B. McCarl: A Representation and Economic Interpretation of a Two-level Programming Problem, Journal of the Operational Research Society, 32, 783/792 (1981)

10) J.F. Bard: Convex Two-Level Optimization, Mathematical Programming, 40, 15/27 (1988)

11) K. L. Hoffman: A Method for Globally Minimizing Concave Functions over Convex Sets, Mathematical Programming, 20, 22/32 (1981)

12) T.V. Thieu, B. T. Tam and V.T. Ban: An Outer Approximation Method for Globally Minimizing a Concave Function over a Compact Convex Set, Acta Mathematica Vietnamica, 8, 21/40 (1983)

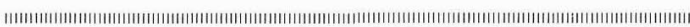
[著 者 紹 介]

呂敏 (学生会員)

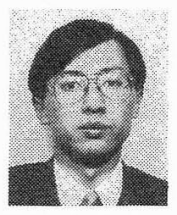

1984 年, 中国西安交通大学情報制御工学 科卒業. 1989 年慶応義塾大学大学院理工学 研究科修士課程修了. 1992 年同博士課程修 了. 現在, 千代田化工建設(株)に勤務。2 レベル計画問題などの大域最適化手法に関 する研究に従事。(工学博士)

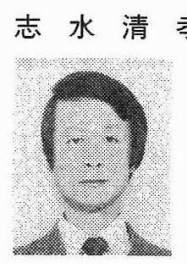

\section{(正会員)}

1962 年, 慶応義塾大学理工学部計測工学 科卒業. 1964 年同大学大学院修士課程修 了. 1967 年ラース工科人学博士課程修了. Ph. D.. 現在, 慶大理工学部教授. 専門はシ ステム制御, 数理計画法, 最適制御など. Sigma Xi などの会員. 著書「多目的と競争 の理論」「数理計画法」など. 